\title{
Race, Ethnicity, and Perceived Minority Police Presence: Examining Perceptions of Criminal Injustice Among Los Angeles Residents
}

\author{
Xia Wang \\ Garth Davies
}

Justin Ready

\begin{abstract}
Although the conventional wisdom holds that increasing the number of minority officers will enhance residents' perceptions of police and the criminal justice system, further systematic investigation of this hypothesis may be needed. Building on the group-position thesis, the representative bureaucracy theory, and prior research, this study investigates whether perceived minority police presence within residents' neighborhoods affects residents' perceptions of criminal injustice, whether this effect is more pronounced for minority residents and in minority neighborhoods, and whether perceived minority police presence has a stronger effect on perceptions of criminal injustice for minority residents in more integrated and white neighborhoods than minority residents in minority neighborhoods. Analyses of data collected from Los Angeles, CA, show that residents perceive a lower level of criminal injustice when they report that officers in their neighborhoods are not white-dominated, and this finding is not dependent on the respondent's race/ethnicity or the racial/ethnic composition of the neighborhood. In addition, perceived minority police presence seems to have a weak to no effect on residents' perceptions of criminal injustice for Hispanic communities. We discuss these findings and their implications for theory, research, and policy.
\end{abstract}

A

racially and ethnically diverse police force is now widely accepted and positively viewed in American political and law enforcement circles (Weitzer and Tuch 2004a: 397; see also President's Task Force on 21 st Century Policing 2015). Although the conventional wisdom holds that increasing the number of minority officers will enhance residents' perceptions of police, only a small number of studies have directly examined this hypothesis. Such studies, when using aggregate data,

We want to especially thank Daniel Mears for his feedback on the previous draft. We also want to thank Scott Decker, Robert Kane, Mike Reisig, and Eric Stewart for their helpful comments and suggestions and Natalie Todak for her research assistance. We extend special thanks to Hubert Williams, the Police Foundation, and the Bradley Foundation for supporting the data collection. The views expressed in this article are those of the authors and do not necessarily reflect those of the Police Foundation and the Bradley Foundation. Furthermore, we are very grateful to the Editors and anonymous reviewers for their constructive feedback and insights.

Please direct all correspondence to Xia Wang, School of Criminology and Criminal Justice, Arizona State University, 411 N. Central Ave, Suite 600, Phoenix, AZ 85004; e-mail: xiawang@asu.edu. 
have found that black residents in cities with higher numbers of black officers held more positive views of the local police department than their counterparts in cities with low numbers of black officers (Decker and Smith 1980; see also Skogan 1979). More recently, several studies have examined the effect of minority police presence on residents' complaints of police and produced mixed findings. ${ }^{1}$ For example, although Hickman and Piquero (2009) found that minority representation of police officers did not significantly affect the rate of residents' complaints about police use of force and the percentage of force complaints that are sustained (see also Cao and Huang 2000), Cao et al. (2000) found that percentage of black officers increased the rate of residents' complaints and Hong (2017a) reported that increasing the representation of ethnic minorities in police departments in England and Wales reduced the number of residents' complaints against police misconduct. Overall, using macrolevel data, prior studies not only produced mixed findings but also suffered from a lack of individual-level controls, thus rendering the results regarding group- or individuallevel processes ambiguous (Quillian 1995: 590; see also Theobald and Haider-Markel 2009).

Using individual-level data, several studies have found that officer race has limited significance for residents' attitudes (Brunson and Gau 2015; Lasley 1994; Weitzer 2000). Furthermore, studies examining the interaction effect between officer race and resident race on attitudes about police actions have produced inconclusive findings: although some did not find the officer-driver race interaction had a significant effect (e.g., Engel 2005; Langan et al. 2001), others reported that minority residents were more likely to perceive police actions as legitimate if there were minority officers present (Novak et al. 2012; Theobald and Haider-Markel 2009). Moreover, several single-city case studies conducted with majority-black police departments have generated mixed findings regarding the potential effect of minority police on residents' attitudes toward police. Specifically, Frank et al. (1996) found that black respondents had more favorable attitudes toward police than white respondents in Detroit and explained this "unconventional" finding by highlighting that nearly 50 percent of the police force in Detroit is black, "as are the Chief and a substantial number of administrators in the department" (Frank et al. 1996: 332). However, other single-city case studies indicate that the majority-black police departments may not improve black residents' views (see Howell et al. 2004; Welch et al. 2001). Overall, prior individual-level studies produced inconclusive findings

\footnotetext{
1 Scholars have conceptualized residents' complaints as an indicator of police performance (Wagner and Decker 1993) or the quality of police-public interactions (Hickman and Piquero 2009). Most relevant to this study, residents' complaints have also be viewed as an important measure of public perceptions of the police (Cao et al. 2000; Cao and Huang 2000).
} 
and failed to allow researchers to directly assess the effect of minority group representation in police force on individual perceptions of criminal injustice (Ward 2006).

Most recently, using individual-level data, Riccucci et al. (2018) examined whether varying the representation of black officers in local agencies influenced how black and white respondents viewed the police. Specifically, by using an online survey experiment that varies the representation of black officers $(85$ percent black officers and 15 percent white officers vs. 15 percent white officers and 85 percent black officers) in a hypothetical police department and also varies the agency's complaints of police misconduct, Riccucci et al. found that perceived police performance, trust, and fairness improved among black respondents when the police force was composed of mostly black officers. Although this study and other prior studies are very insightful, a number of questions remain. First, extant studies primarily consist of analyses using objective measures of department-level minority police presence, so we know little about the effect of minority police presence within residents' neighborhoods. This oversight is significant because residents exposed to a racially and ethnically diverse police force in their own communities are more likely to observe it, which in turn may generate a greater impact on their perceptions. Furthermore, it is important to investigate perceived minority police presence, because minority representation can be more consequential for individual perceptions if individuals situated in the circumstance are aware of and concerned about it (Chiricos et al. 2001: 323), and "human perceptions of situations have real importance even when perceptions might be wrong" (Theobald and Haider-Markel 2009: 411). A number of studies have found that perceived, not objective, racial composition has consequences for individual perceptions and attitudes (e.g., Chiricos et al. 1997; Semyonov et al. 2004; Wang 2012). Second, it is unknown as to how minority police presence, perceived or actual, would affect Hispanic residents' perceptions of criminal injustice. This oversight is notable because, per the 2010 census, Hispanics are the largest minority group in the United States, representing 16 percent of the population. Moreover, Hispanic residents have increasingly been the focus of searches for immigration violations, which might shape their views of police and foster distrust in the justice system (Martinez 2007). Third, limited attention has been paid to assessing the interactive effects between minority police presence, perceived or actual, and residents' race/ethnicity or neighborhood racial/ethnic context, and it is unknown about the effect of minority police presence for minority residents in more integrated and white neighborhoods versus its effect for minority residents in minority neighborhoods. This is a significant oversight, because differences in racial and ethnic orientations may need to be conceptualized in terms of "cognitive landscapes" (Sampson and Bartusch 1998: 800). 
The goal of this article is to contribute to research aimed at understanding how perceptions of minority group representation of criminal justice agents influence residents' perceptions of criminal injustice. It is vital to consider how to improve individual perceptions of criminal justice, especially among minority residents, because perceptions of criminal injustice are "so consequential for both the frequency of crime and the collective efforts among neighborhood residents to control crime" (Kirk and Matsuda 2011: 466-67), and these perceptions can also affect racial and larger political tensions. Furthermore, "Given that departments are under relatively strong political pressure (and also legal pressure) to diversify as a matter of policy, research demonstrating any effect of minority representation on police performance or public perception of police performance is important" (Hickman and Piquero 2009: 22). Our main theoretical contribution is to assess to what extent the group-position thesis and the representative bureaucracy theory are supported when investigating the main and interactive effects of perceived minority police presence on residents' perceptions of criminal injustice. Consistent with the group-position thesis, the representative bureaucracy theory, and prior research, we use "minority" in this article to refer to people of color.

\section{Background}

The issue of how individuals perceive legal authorities has garnered considerable attention from researchers. In particular, Sampson and Bartusch (1998) first used legal cynicism to describe distrust of the law and legal authorities, but research on legal cynicism has primarily paid attention to criminal justice, especially policing (Bell 2016). Research has consistently found that black and Hispanic residents hold lower levels of trust and confidence in the police and perceive a lower level of police legitimacy than whites (Engel 2005; Kochel 2017; Novak et al. 2012; Theobald and Haider-Markel 2009; Tyler 2004, 2005, 2011; Weitzer et al. 2008; Weitzer and Tuch 2006). In a 2016 study conducted by the Pew Research Center, Morin and Steple (2016) found that 75 percent of white respondents, compared with 35 percent of black respondents and 58 percent of Hispanic respondents, indicated that the local police department did an excellent or good job in treating racial and ethnic groups equally. The sources of legal cynicism may be complex (Bell 2016: 319). For example, differences in racial and ethnic orientations may be rooted in experiential differences associated with neighborhood context and thus conceptualized in terms of "cognitive landscapes" (Sampson and Bartusch 1998: 800). In addition, legal cynicism may be due to lack of racial diversity in police force because for many black residents, "police have come to 
symbolize white power, white racism and white repression" (National Advisory Commission on Civil Disorders 1968: 10).

Meanwhile, social psychology has contributed to this research largely through the procedural justice perspective which maintains that police legitimacy is related to public evaluations about the fairness of the processes through which the police make decisions and exercise authority (Sunshine and Tyler 2003: 514; see also Tyler 2004, 2011). A number of studies have examined the influence of general evaluations of police use of procedural justice on individual perceptions of police legitimacy, finding that when police are perceived to exercise their authority fairly in a general manner, they are viewed as more legitimate (e.g., Elliott et al. 2011; Murphy et al. 2008; Reisig et al. 2007; Tyler and Wakslak 2004). ${ }^{2}$ Although this perspective is highly insightful, it has focused little on neighborhood context (Bell 2016: 319) or racial diversity in police force.

\section{The Group-Position Thesis and the Representative Bureaucracy Theory}

The group-position thesis contends that intergroup relations are largely driven by group competition and conflict over resources, power, and status (Blumer 1958). Criminal justice institutions, including the police, are considered instrumental in serving the interests of the dominant group, and they are viewed as "key mechanisms in the control of subordinate groups and in the protection of dominantgroup interests" (Weitzer and Tuch 1999: 495; see also Unnever and Cullen 2005, 2007a, 2007b). Thus, black and Hispanic residents may be more inclined to view the criminal justice system as a "visible sign of majority domination" (Bayley and Mendelsohn 1969: 195).

Furthermore, if a group's position relative to the dominant group shapes its members' attitudes, Weitzer and Tuch (2006: 8-14) argued that when the police force is not white dominated, black and Hispanic residents may have more positive attitudes toward police as they may feel that their group interests could be advanced by greater control over the criminal justice system (Weitzer and Tuch 2004b: 306). In addition, greater presence of minority officers may be "symbolically significant to the appearance of system legitimacy" (Ward 2006: 69) and legitimize "the apparatus of social control" (Barlow and Barlow

${ }^{2}$ Our conceptualization of criminal injustice is very similar to distributive injustice, or distributive unfairness, which reflects public judgments that police resources and services are allocated unfairly across individuals (see Sunshine and Tyler 2003). Police legitimacy, however, is conceptualized as the "belief that legal authorities are entitled to be obeyed and that the individual ought to defer to their judgments" (Tyler and Huo 2002: xiv). Whereas some argue that distributive injustice is exogenous to the procedural justice model (see Reisig et al. 2007), others argue that it is an element in the legitimacy model (see Tankebe et al. 2016). Although the measurement of legitimacy is extremely important, this issue is beyond the scope of this article. 
2000: 246). Weitzer's (2000) research, for example, indicates that both black and white residents view the entire police department as more legitimate as police agencies are diversified. Also relevant to this study is the representative bureaucracy theory that contends when minorities are better represented in state institutions (e.g., police), feelings of inclusion may lead them to view the actions of the institutions as more legitimate (Theobald and Haider-Markel 2009: 414; see also Mansbridge 1999; Ozkan et al. 2016; Riccucci et al. 2018).

An alternative mechanism by which minority police presence affects perceptions of criminal injustice is through objective policing (Sherman 1983; Ward 2006). Research on the relationship between officer race and policing has generally yielded mixed findings. For example, the National Research Council's Committee to Review Research on Police Policy and Practices (Skogan and Frydl, 2004; see also Alpert and Dunham 1998, 2004; McElvain and Kposowa 2004) found no evidence of a relationship between officers' race and their decision to arrest or use force. However, a few studies found that white officers were more likely to conduct a search (Close and Mason, 2007; Rojek et al., 2012), ticket traffic-law violators (Gilliard-Matthews et al. 2008), make arrests (Brown and Frank 2006; Close and Mason, 2006), or use deadly force (McElvain and Kposowa 2008; but see Geller and Karales 1981). Furthermore, although some found that black officers were less biased toward black residents (e.g., Antonovics and Knight 2009; Anwar and Fang, 2006; Fagan et al. 2016), others found the opposite (e.g., Brown and Frank 2006; Novak et al. 2012; Sun and Payne 2004). Moreover, prior research has reached no conclusion regarding the effect of a diverse police force (Legewie and Fagan 2016; Weitzer 2015), which is not surprising because of similarities among officers in their policing activities resulting from their similar training and on-the-job socialization (see Forman 2002, 2017). Specifically, Smith (2003) found that more diversified departments did not have significantly lower levels of police-caused homicides (see also Legewie and Fagan 2016) or lower black order-maintenance arrests (Sharp 2014), whereas Hong (2017b) reported that minority representation in police significantly reduced racial profiling in England and Wales or deadly force in large U.S. cities but not in small cities (Willits and Nowacki 2014). Most recently, using data on policeinvolved homicides in 2014 and 2015 in large U.S. cities, NicholsonCrotty et al. (2017) found that an increase in black officers reduced the number of homicides of blacks by police officers but only once the proportion of black officers was sufficiently large.

\section{Hypotheses}

Building on the group-position thesis, the representative bureaucracy theory, and prior research, we develop four hypotheses. In 
particular, we hypothesize that perceived minority police presence will be associated with lower levels of perceptions of criminal injustice (hypothesis 1).

The logic of the group-position thesis suggests that in places where black and Hispanic residents gain power and control over criminal justice resources, their views toward the criminal justice system may be more positive (Barlow and Barlow 2000). In addition, the representative bureaucracy theory suggests that when minorities are better represented in police, feelings of inclusion may lead them to view police actions as more legitimate (Theobald and HaiderMarkel 2009). In fact, black residents were significantly more likely than white residents to report that increasing the proportion of minority officers would improve police trust (Kochel 2017). Thus, we hypothesize that perceived minority police presence will be more strongly associated with perceptions of criminal injustice for black and Hispanic residents than their white counterparts (hypothesis 2).

Furthermore, perceived minority police presence may have a more pronounced effect for residents in neighborhoods with large concentrations of subordinate-group members. Residents in those neighborhoods may have very limited or no ability to influence the structures of power that constrain their lives, which may foster negative views of the criminal justice system (Sampson and Bartusch 1998: 783; see also Kirk and Matsuda 2011; Kirk and Papachristos 2011). ${ }^{3}$ Meanwhile, perceiving greater minority police presence may produce perceptions of greater balance in power and influence (Ward 2006), which may alleviate the pernicious effect of neighborhood disadvantage on residents' perceptions of criminal justice. Thus, we hypothesize that perceived minority police presence will be more strongly associated with perceptions of criminal injustice for residents in minority neighborhoods, regardless of their racelethnicity, as compared with residents in white neighborhoods (hypothesis 3).

Last, perceived minority police presence may be especially useful in promoting positive perceptions of the police for

${ }^{3}$ Although scholars have paid more attention to poor minority neighborhoods, less attention has been paid to middle-class and affluent minority neighborhoods (Pattillo 2013). Thus, we may not know if residents in those neighborhoods also have very limited ability to influence the structure of power. That said, a small body of research has found that middle-class and affluent black neighborhoods, usually contiguous to areas of concentrated poverty, are often characterized by "resource deficits" (Pattillo 2005: 317) and "more poverty, higher crime, worse schools, and fewer services than white middle-class neighborhoods" (Pattillo 2013: 3; see also Adelman 2004). "Even the most affluent blacks are not able to escape from crime, for they reside in communities as crime-prone as those housing the poorest whites" (Alba et al. 1994: 427; see also Logan and Stults 1999). As a result of the resource deficits and socioeconomic diversity, black middle-class neighborhoods may have difficulty in "coalescing around particular interests to advance policy initiatives or to elect representatives in large numbers," thus they may not have control over "many of the important power levers" (Pattillo 2005: 315; see Ginwright 2002; Johnson, 2012). Overall, minority residents, even in middle-class and affluent minority neighborhoods, may still have limited ability to influence the structure of power. 
minority residents in more integrated and white neighborhoods. Sampson and Bartusch (1998: 800) used "cognitive landscape" to describe the ecological structuring of neighborhoods where "institutions of criminal justice are mistrusted." As further explained by Hagan et al. (2005: 385), black and Hispanic residents' perceptions of criminal injustice may be influenced by their level of exposure to other and more advantaged groups in a surrounding neighborhood. Specifically, black and Hispanic residents in minority neighborhoods may be more inclined to restrict their frame of references to their immediate community where police attention is frequent and familiar, whereas black and Hispanic residents in more integrated or white neighborhoods may develop multiple reference groups, which allows them to compare their experiences to white and other racial groups and observe and experience racial biases, so that they may be even more inclined to view police negatively (see also Brooks 2000). Therefore, we hypothesize that perceived minority police presence will be more strongly associated with perceptions of criminal injustice for black and Hispanic residents in more integrated and white neighborhoods, as compared with their black and Hispanic counterparts in black and Hispanic neighborhoods (hypothesis 4). ${ }^{4}$

\section{Data and Methods}

We use household survey data collected in Los Angeles, California, to test our hypotheses for two reasons. First, Los Angeles is characterized by extensive racial and ethnic diversity. According to the 2000 census, black, Hispanic, white, and Asian residents represent 11.2 percent, 46.5 percent, 46.9 percent, and 10 percent of the population, respectively. ${ }^{5}$ Second, Los Angeles has a racially and ethnically diverse police force, partly due to two consent decrees, one in 1981 and the other in 1992, that required the Los Angeles Police Department (LAPD) to recruit more minority officers and ensure fair practices in their training and promotion (Stone et al. 2009). In 2000, 53.9 percent of full-time sworn personnel in LAPD were

4 The difference between hypotheses 3 and 4 has implications for the analysis. To test hypothesis 3 , we split the full sample to respondents in minority neighborhoods versus respondents in white neighborhoods. To test hypothesis 4, we split the black (or Hispanic) sample to black (or Hispanic) respondents in black (or Hispanic) neighborhoods versus black (or Hispanic) respondents in white and integrated neighborhoods.

${ }^{5}$ We present the 2000 statistics as our survey data were collected in 2001 . The sum of these percentages is over 100 percent because the 2000 census treats race and ethnicity as being separate and distinct, and Hispanic residents are defined also as white or black. Per the 2010 census, black, Hispanic, white, and Asian residents represent 9.2 percent, 48.3 percent, 27.2 percent, and 14.6 percent of the population, respectively. 
minority, including 13.6 percent black and 33.1 percent Hispanic (Reaves and Hickman 2002: 11). ${ }^{6}$

The survey data were collected using a multistage cluster sample of households in the City of Los Angeles in 2001. Specifically, clusters of block groups that contained over 80 percent white households, over 80 percent Hispanic households, or over 80 percent black households were identified separately, and from each of the clusters, a random sample of 20 block groups was selected. ${ }^{7}$ From each of these 60 block groups, a random sample of 25 households was selected, resulting in a sample of 1250 adult residents. Due to boundary changes between 1990 and 2000 census, 60 block groups in 1990 were expanded to 241 block groups. So our analysis is based on 1250 residents nested in 241 block groups. ${ }^{8}$

To conduct telephone interviews using computer-assisted telephone interviewing, contact information for the sampling frame was derived in a two-stage process. First, ArcView GIS software was used to identify all addresses within each of the selected block groups. Second, a computerized reverse telephone directory was then used to identify the phone numbers for each selected block group. The household survey contained questions inquiring about respondents' demographic, social, and economic characteristics, the frequency and nature of their encounters with police in the past year, and their perceptions of criminal injustice. The telephone interview took an average of 20 minutes to complete. The response rate for the survey was $46 \%{ }^{9}$

${ }^{6}$ Individual perceptions of neighborhood minority police presence are different from these department-level objective statistics. In fact, whereas the department-level statistics indicate that over half of full-time sworn personnel in LAPD were minority and thus the department was actually not mostly white, only 63 percent of our respondents described the officers in their neighborhood as not mostly white. As our findings suggest, variations in perceptions of neighborhood minority police presence are consequential for perceptions of criminal injustice. Thus, it is important to examine the perceptual measure of neighborhood-level minority police presence and factors shaping these perceptions.

${ }^{7}$ The 1990 census data were initially used to determine the racial and ethnic characteristics and population density of all block groups as the 2000 census data were still unavailable when the survey was conducted.

${ }^{8}$ We compared our sample with the general population in Los Angeles, based on the 2000 census, with respect to several sociodemographic characteristics (see Supporting Information Appendix A). Our sample consists of a larger proportion of female, black, and Hispanic respondents and households that made less than $\$ 25,000$ than the Los Angeles population. Male and white respondents, respondents of other racial minority, and households that had more than $\$ 25,000$ annual income are under-represented in our sample. Age distribution is largely similar. Overall, our sample seems to be modestly representative of the Los Angeles population.

${ }^{9}$ Response rates for telephone interviews have declined since 1979 (Curtin et al. 2005). McCarty et al. (2006) found that the modal response rate of 80 surveys was 25 percent. Furthermore, several studies found little evidence for a relationship between response rates and nonresponse bias in random digit dialing telephone surveys (Curtin et al. 2000; Keeter et al. 2006). 


\section{Dependent Variable}

Our dependent variable, perceptions of criminal injustice, is comprised of four indicators. Respondents were asked whether they strongly agree $(=1)$, agree $(=2)$, disagree $(=3)$, or strongly disagree $(=4)$ with the following four statements:

1. The police in your neighborhood treat people of all races equally.

2. In similar situations, the police are more likely to stop people who are not white for a traffic violation than people who are white.

3. In similar situations, the police are more likely to use force against people who are poor than against people who are not poor.

4. In similar situations, the police are more likely to use physical force against people who are not white than against people who are white.

We reversed the coding for the last three statements so that, for each item, higher scores indicated that respondents perceived a higher level of criminal injustice. ${ }^{10}$ Following Hagan et al. (2005: 388 ), we added the responses across these four items to compose a scale on perceptions of criminal injustice (Cronbach's alpha $=0.84$ ).

\section{Perceived Minority Police Presence}

Perceived minority police presence is measured by a dummy variable and coded as " 0 " if the respondent describes officers in his or her neighborhood as mostly white and " 1 " if the respondent describes officers as not mostly white. We select this dichotomy for two reasons. First, the group-position thesis, the representative bureaucracy theory, and prior research suggest that residents in places patrolled by more racially mixed police may perceive a lower level of injustice than their counterparts in places patrolled by white-dominated (i.e., mostly white) police, thus the dichotomy of mostly white versus not mostly white officers may be most consequential for perceptions of criminal injustice. Second, it may be a more clear distinction for residents to determine whether officers are mostly white or not rather than to decide on continuous gradations of racial composition. ${ }^{11}$

\section{Control Variables}

We include a number of controls that are potentially correlated with perceptions of criminal injustice. Race is a dummy

${ }^{10}$ We include a class component in the construction of perceptions of criminal injustice, because "race and class conflict exist with regard to issues of criminal injustice, and neither kind of conflict can properly be understood without consideration of the other" (Hagan and Albonetti 1982: 329).

11 That said, future research may want to include additional survey items that capture perceived minority police presence. 
variable and coded " 1 " if the respondent defines him or herself as black or African American. Ethnicity is also a dummy variable and coded " 1 " if the respondent defines him or herself as Hispanic or Latino. We also construct an "other race" variable comprised of Asian and other racial and ethnic respondents. Whites are the reference group in the full sample analysis.

Prior research suggests that youth and men are more likely to embrace negative views of the police (e.g., Brunson 2007; Brunson and Miller 2006), so we control for age (in years) and male ( $1=$ yes, $0=$ no). Because the respondent's income and employment status may be related to perceptions of criminal injustice (e.g., Hagan and Albonetti 1982), we control for self-reported income $(1=$ less than $\$ 10,000,2=$ between $\$ 10,000$ and $\$ 25,000,3=$ between $\$ 25,000$ and $\$ 40,000,4=$ between $\$ 40,000$ and $\$ 60,000,5=$ more than $\$ 60,000$ ) and include unemployment ( $1=$ not working, $0=$ otherwise $)$. In addition, we control for length of time the respondent has been living at the current address and the frequency of attending religious services, because these factors may impact perceptions of criminal injustice (e.g., Unnever et al. 2011). Furthermore, we include police visibility because neighborhoods may differ in the overall amount of policing that they receive (Klinger 1997), which may influence residents' perceptions of the police. Police visibility is measured by responses to the following question: "Do you see police officers in your neighborhood (1) not at all, (2) a few times a year, (3) about once a month, (4) about once a week, (5) a few times a week, or (6) every day?" Last, we control for the frequency of involuntary police contacts (see Brown and Benedict 2002; Decker 1981; Scaglion and Condon 1980) and voluntary police contacts (see Huebner et al. 2004; Reisig and Parks 2000). Respondents were asked: "In the past year, how many times have you been stopped by the police while driving in L.A.?" and "In the past year, how many times have you been stopped by the police while standing or walking in a public place?" We added responses of these two items and constructed an ordinal variable to reflect the frequency of involuntary police contacts $(0=$ never, $1=1-2$ times, $2=3-5$ times, $3=$ more than 5 times). We constructed voluntary police contacts based on a question asking the respondent how many times he or she called the police to report a problem in his or her home or neighborhood in the past year $(0=$ never, $1=1-2$ times, $2=3-5$ times, $3=$ more than 5 times). Table 1 presents the descriptive statistics for all the study variables and Supporting Information Appendix B provides the bivariate correlations.

\section{Analytic Strategy}

Of the 1250 respondents, 37 did not provide a valid answer to any of the four indictors used to construct the dependent variable 
and were excluded from the analysis. Unfortunately, 22.8 percent of our survey data have missing values on one or more variables included in the analysis. Because multiple imputation is "one of the most attractive methods for general-purpose handling of missing data in multivariate analysis" (Allison 2000: 301), we performed multiple imputation in Mplus 7 to address the missing data problem. We used all the variables included in the subsequent analysis for multiple imputation, including all four indicators used to construct the dependent variable. In addition, in accordance with recommended approaches to multiple imputation (see Acock 2005: 1026), we incorporated a number of supplementary variables, such as a variable reflecting if anyone else in the respondent's household called or was stopped by the police in the past year, a variable indicating if the respondent owns his or her home, and a variable reflecting if the respondent or any of his or her family or friends are sworn police officers. Ten imputations in total were performed because "unless rates of missing information are unusually high, there tends to be little or no practical benefit to using more than five to ten imputations" (Schafer 1999: 7).

Next, we use ordinary least square (OLS) regression to assess the effect of perceived minority police presence on individual perceptions of criminal injustice. We conduct our analysis with the multiply-imputed datasets in Mplus 7 and obtain robust standard errors computed using the sandwich estimator to take into account the nonindependence of respondents within the same block groups (see Muthén and Muthén 1998: 251). ${ }^{12}$ To investigate if the effect of perceived minority police presence is more pronounced for minority residents (hypothesis 2) and in minority neighborhoods (hypothesis 3) and whether this effect is stronger for minority residents in more integrated and white neighborhoods than for minority residents in minority neighborhoods (hypothesis 4), we perform a set of z-tests. A z-test is used to assess the statistical significance of the difference between regression coefficients that have been estimated in two independent samples (Paternoster et al. 1998). For example, when we test whether the relationship between perceived minority police presence and individual perceptions of criminal injustice is of the same magnitude for white versus black respondents, we use the formula below,

$$
z=\frac{b_{1} b_{2}}{\sqrt{\mathrm{SE} b_{1}^{2}+\mathrm{SE} b_{2}^{2}}}
$$

12 The number of respondents nested in the respective block groups averages 5 , and approximately 40 percent of the block groups include only one respondent. Thus, too few respondents per block group precludes the use of hierarchical linear modeling. 
Table 1. Descriptive Statistics

\begin{tabular}{|c|c|c|c|c|}
\hline & \multicolumn{4}{|c|}{ Mean (s.d.) } \\
\hline & $\begin{array}{c}\text { Full } \\
(\mathrm{N}=1213)\end{array}$ & $\begin{array}{c}\text { White } \\
(\mathrm{N}=326)\end{array}$ & $\begin{array}{c}\text { Black } \\
(\mathrm{N}=275)\end{array}$ & $\begin{array}{c}\text { Hispanic } \\
(\mathrm{N}=562)\end{array}$ \\
\hline \multicolumn{5}{|l|}{ Dependent Variable } \\
\hline $\begin{array}{l}\text { Perceived Criminal Injustice } \\
\text { Main Variable of }\end{array}$ & $\begin{array}{l}10.63 \\
(2.26)\end{array}$ & $\begin{array}{c}9.95 \\
(2.27)\end{array}$ & $\begin{array}{l}11.80 \\
(2.37)\end{array}$ & $\begin{array}{l}10.47 \\
(1.99)\end{array}$ \\
\hline Perceived Minority & 0.63 & 0.65 & 056 & Main Variable of Interest \\
\hline Police Presence & $(0.48)$ & $(0.48)$ & $(0.50)$ & $(0.48)$ \\
\hline \multicolumn{5}{|l|}{ Controls } \\
\hline Black & $\begin{array}{c}0.23 \\
(0.42) \\
0.46\end{array}$ & & & \\
\hline Hispanic & $\begin{array}{c}(0.50) \\
0.04\end{array}$ & & & \\
\hline \multirow[t]{2}{*}{ Other } & $(0.19)$ & & & \\
\hline & 42.76 & 47.89 & 49.92 & 36.78 \\
\hline Age & $\begin{array}{c}(18.57) \\
0.44\end{array}$ & $\begin{array}{c}(19.22) \\
0.55\end{array}$ & $\begin{array}{c}(19.98) \\
0.41\end{array}$ & $\begin{array}{c}(14.99) \\
0.39\end{array}$ \\
\hline \multirow[t]{2}{*}{ Male } & $(0.50)$ & $(0.50)$ & $(0.49)$ & $(0.49)$ \\
\hline & 0.15 & 0.09 & 0.11 & 0.20 \\
\hline \multirow[t]{2}{*}{ Unemployed } & $(0.35)$ & $(0.28)$ & $(0.31)$ & $(0.40)$ \\
\hline & 2.73 & 3.55 & 2.85 & 2.13 \\
\hline Income & $(1.36)$ & (1.34) & $(1.34)$ & $(1.05)$ \\
\hline Number of Years Living at the & 3.15 & 3.27 & 3.64 & 2.84 \\
\hline Current Address & $(1.68)$ & $(1.77)$ & $(1.82)$ & $(1.49)$ \\
\hline Frequency of Attending & 2.77 & 2.11 & 3.37 & 2.90 \\
\hline \multirow[t]{2}{*}{ Religious Services } & $(1.43)$ & $(1.27)$ & $(1.34)$ & $(1.40)$ \\
\hline & 4.61 & 4.12 & 4.88 & 4.80 \\
\hline \multirow{2}{*}{ Police Visibility } & $(1.53)$ & $(1.58)$ & $(1.40)$ & $(1.47)$ \\
\hline & 0.34 & 0.31 & 0.47 & 0.29 \\
\hline \multirow[t]{2}{*}{ Involuntary Contacts } & $(0.68)$ & $(0.51)$ & $(0.87)$ & $(0.67)$ \\
\hline & 0.29 & 0.28 & 0.31 & 0.28 \\
\hline Voluntary Contacts & $(0.61)$ & $(0.58)$ & $(0.60)$ & $(0.63)$ \\
\hline
\end{tabular}

where $b_{1}$ represents the effect of perceived minority police presence within the white sample, $b_{2}$ is the effect of perceived minority police presence within the black sample, and $\mathrm{SE} b_{1}^{2}$ and $\mathrm{SE} b_{2}^{2}$ are the coefficient variances associated with $b_{1}$ and $b_{2}$, respectively. This hypothesis test follows the structure of a significance test between two sample means and is a $z$-test when the sample is large (Paternoster et al. 1998).

\section{Results}

We conducted multicollinearity diagnostics, and the results of bivariate correlations (Supporting Information Appendix B), variance inflation factors, and condition indices indicated that multicollinearity was not a problem. Then we begin first by presenting results of analyses aimed at testing the main effect of perceived minority police presence on residents' perceptions of criminal injustice.

Review of the full sample analysis in Table 2 shows that perceived minority police presence is negatively and significantly associated with respondents' perceptions of criminal injustice, 
suggesting that residents perceive a lower level of criminal injustice when they describe their neighborhoods as having greater minority police presence. Thus, we find support for hypothesis 1. Meanwhile, we find that black and Hispanic respondents and those who had more involuntary contacts with police perceive a higher level of criminal injustice; respondents in the "other" racial category are no more likely than white respondents to perceive criminal injustice. Given that Asian residents make up a significant proportion of the Los Angeles population, it is reasonable to expect that the other racial category primarily consists of Asian respondents. Thus, our finding is consistent with other research indicating that Asian respondents are no more likely to perceive criminal injustice than white respondents (e.g., Wortley 1996). We also find that older respondents and those who see police officers in their neighborhood more often perceive a lower level of criminal injustice. Furthermore, income is positively and significantly related to perceptions of criminal injustice, which we will discuss in more detail in the Discussion and Conclusion section.

Minority police presence may improve individual perceptions of criminal justice by producing more objectively just outcomes, such as reduced involuntary police contacts. If so, examining the effect of minority police presence on perceptions of criminal injustice, while including involuntary police contacts, will only capture the direct effect of minority police presence, thus ignoring its indirect effect via involuntary contacts and in turn underestimating the total effect of minority police presence on perceptions of criminal injustice. However, as we focus on perceived minority police presence, it is not logical to hypothesize that perceived minority police presence affects involuntary contacts, especially when it is unknown to what extent perceived minority police presence is correlated with the objective measure. That said, we run a path model in ancillary analysis and find that perceived minority police presence affects frequency of involuntary police contacts, which in turn affects individual perceptions of criminal injustice. ${ }^{13}$ The effect of perceived minority police presence on perceptions of criminal injustice is primarily direct as indirect effect of perceived minority police presence via involuntary contacts only accounts for 6 percent of its total effect. This finding is not surprising because the relationship between perceived minority police presence and perceptions of criminal injustice should be primarily direct, rather than through involuntary contacts. Thus, the extent to which our findings are affected by objective differences in policing that may result from perceived minority police presence is very small.

${ }^{13}$ We also assessed if perceived minority police presence affected police visibility and found that the effect of perceived minority police presence on police visibility was not statistically significant. 


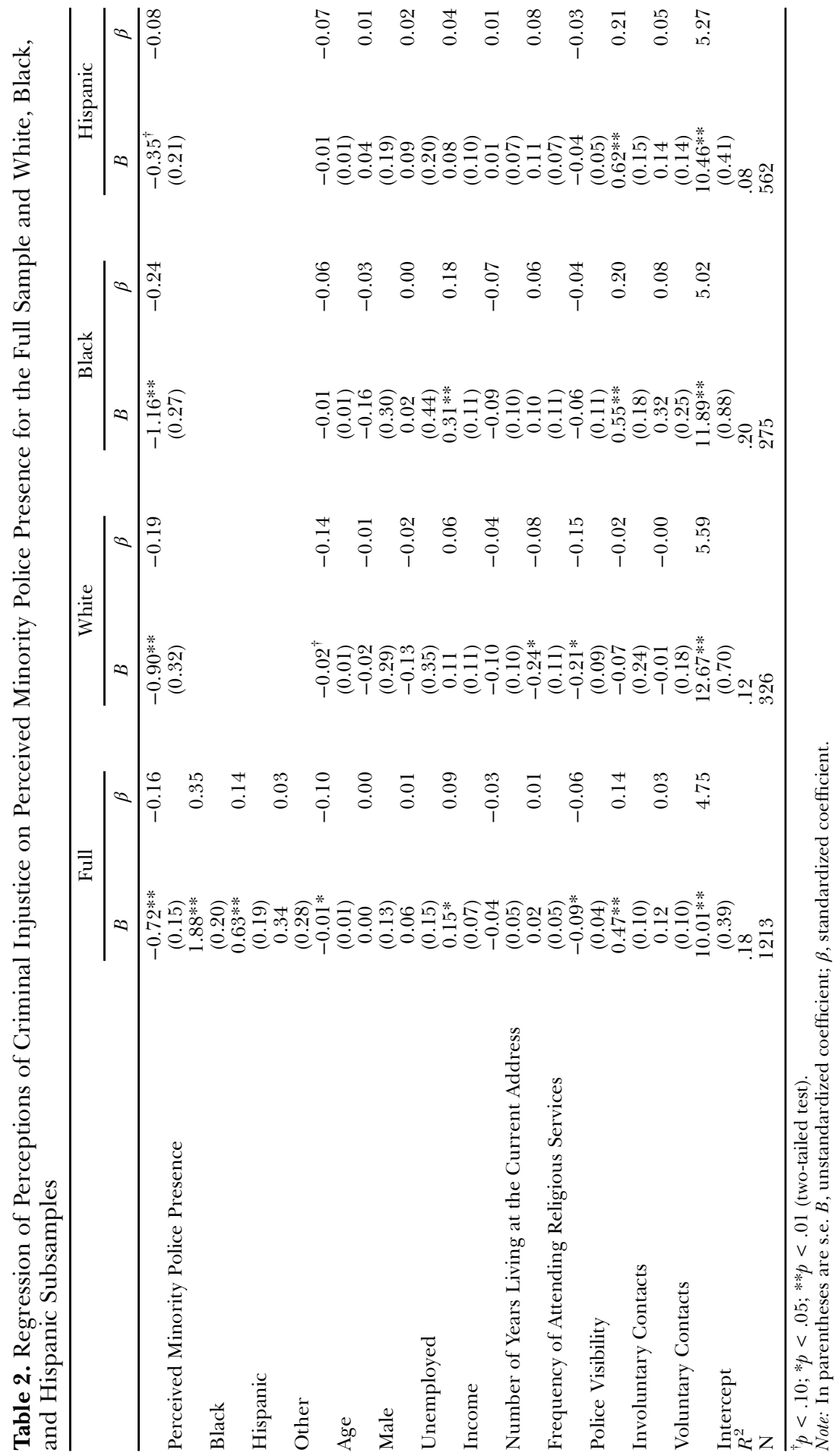


To test hypothesis 2 , which anticipates that the effect of perceived minority police presence will be more pronounced for black and Hispanic residents, we divide the sample into white, black, and Hispanic subgroups and perform OLS separately for each. Inspection of the analyses for the white, black, and Hispanic subgroups in Table 2 suggests that for each subgroup, perceiving greater minority police presence significantly reduces respondents' perceptions of criminal injustice. Furthermore, we perform a set of $z$-tests, which reveal that the effect of perceived minority police presence is not significantly different for white versus black respondents $(z=-0.63, p>.10)$ or Hispanic respondents $(z=1.45, p>.10){ }^{14}$ Thus, we fail to find support for hypothesis $2 .{ }^{15}$

Notably, although involuntary police contacts increase perceptions of criminal injustice for black and Hispanic respondents, they do not significantly affect white respondents' perceptions (see also Wortley et al. 1997). Z-tests further suggest that the effect of involuntary police contacts is significantly different for white versus black respondents $(z=-2.07, p<.05)$ or Hispanic respondents $(z=-2.44, p<.05)$. The differential effect of involuntary police contacts for white versus minority respondents may be due to different types of police stops they experienced-investigatory stops versus traffic-safety stops (Epp et al. 2014). Whereas trafficsafety stops are based on legal evidence about whether a serious traffic violation has occurred, investigatory stops are often justified by weak or no evidence, and officers commonly use relatively minor infractions as a pretext for investigating vehicles and people whom they consider suspicious. Race plays little role in trafficsafety stops, but black drivers are disproportionately stopped for investigatory stops which are "racially framed, institutionally supported" practices that "grow from and reproduce negative racial stereotypes" (Epp et al. 2014: 12). As white drivers almost exclusively experience traffic-safety stops and black drivers often experience investigatory stops, white residents are generally more positive about the stops that they have experienced and black residents commonly view stops that they have experienced as unfair (Epp et al. 2014: 8). Thus, investigatory stops may fuel distrust of police among those who experience this type of stops, primarily

14 The effect of perceived minority police presence on individual perceptions of criminal injustice is significantly different between black respondents and Hispanic respondents $(z=-2.37, p<.05)$.

15 The group-position thesis may also predict that white residents' perceptions of criminal injustice will increase as they perceive police as not mostly white, because a larger number of minority officers may threaten white residents' control over the police. However, our questions measuring perceptions of criminal injustice only ask about the treatment of minorities and do not capture the possibility that the system is biased against white residents. 
people of color, and different types of stops may explain why involuntary police contacts have differential effects on perceptions of criminal injustice for white versus minority residents.

Next, we test hypothesis 3 which anticipates that perceiving greater minority police presence will be more strongly related to perceptions of criminal injustice in minority neighborhoods. Following Peterson and Krivo (2010: 47), we create five types of ethnoracial neighborhoods based on 2000 block-group-level racial and ethnic composition, including white neighborhoods (if a block group has 70 percent or more white residents), black neighborhoods (if a block group has 70 percent or more black residents), Hispanic neighborhoods (if a block group has 70 percent or more Hispanic residents), minority neighborhoods (if a block group has 70 percent or more black and Hispanic residents), and integrated neighborhoods (if a block group has any other racial-ethnic combinations). ${ }^{16}$ Supporting Information Appendix C presents descriptive statistics for all study variables in each type of ethnoracial neighborhoods. We perform OLS separately for each type and present the results in Table 3.

Inspection of Table 3 suggests that the effect of perceived minority police presence is negative in all five types of neighborhoods and statistically significant in all except Hispanic neighborhoods. Furthermore, we perform a set of $z$-tests, which reveal that the effect of perceived minority police presence is not significantly different in white neighborhoods versus black neighborhoods $(z=-0.56, p>.10)$, or Hispanic neighborhoods $(z=-1.26$, $p>.10)$, or minority neighborhoods $(z=-0.72, \mathrm{p}>.10) .{ }^{17}$ We conduct another set of $z$-tests to compare if the effect of perceived minority police presence is significantly different in integrated

${ }^{16}$ Here, we use 70 percent cutoff, instead of 80 percent that was used in the sampling strategy, because doing so allows us to include more respondents in different types of ethnoracial neighborhoods. Recall that 60 block groups that had 80 percent whites, or 80 percent blacks, or 80 percent Hispanics in 1990 were expanded to 241 block groups due to boundary changes between 1990 and 2000 census. Thus, our respondents were dispersed into 241 block groups that had a wider range of density and using 80 percent cutoff would significantly reduce the number of respondents in different types of ethnoracial neighborhoods. For example, whereas there were 142 respondents within 24 black neighborhoods when we used 70 percent cutoff, there were only 69 residents within 12 black neighborhoods when we used 80 percent cutoff. Consequently, using 80 percent cutoff would significantly limit our ability to conduct analysis in different types of ethnoracial neighborhoods. For this pragmatic reason and to be consistent with Peterson and Krivo's (2010) premier research in creating five types of ethnoracial neighborhoods, we use 70 percent cutoff.

${ }^{17}$ We ran a set of ancillary analysis by splitting the sample to respondents in neighborhoods with large concentrations of subordinate-group members (black neighborhoods, Hispanic neighborhoods, and minority neighborhoods) versus those in integrated neighborhoods and white neighborhoods. Our z-test indicates that the effect of perceived minority police presence is not significantly different between these two types of neighborhoods (results available upon request). 
neighborhoods versus black neighborhoods, Hispanic neighborhoods, or minority neighborhoods and find no significant difference. Thus, hypothesis 3 is not supported. ${ }^{18}$

Last, we test hypothesis 4 which anticipates that perceiving greater minority police presence will be more strongly related to individual perceptions of criminal injustice for black and Hispanic residents in more integrated and white neighborhoods than black and Hispanic residents in black and Hispanic neighborhoods. Review of Table 4 indicates that perceived minority police presence significantly reduces black respondents' perceptions of criminal injustice in black neighborhoods. Because very few black respondents lived in integrated and white neighborhoods $(\mathrm{N}=13)$, we could not assess the effect of perceived minority police presence on black respondents' perceptions of criminal injustice in integrated and white neighborhoods, and it is unknown if the effect of perceived minority police presence is stronger for black respondents in integrated and white neighborhoods than black respondents in black neighborhoods. Furthermore, we find that perceived minority police presence is not significantly associated with Hispanic respondents' perceptions of criminal injustice in either Hispanic neighborhoods or integrated and white neighborhoods. Thus, we find no support for hypothesis 4 .

\section{Discussion and Conclusion}

Building on the group-position thesis, the representative bureaucracy theory, and prior research, we developed and tested a series of hypotheses using household survey data collected in Los Angeles. The main findings can be summarized as follows. First, perceived minority police presence significantly reduces residents' perceptions of criminal injustice, suggesting that perceived minority police presence may promote residents' perceptions of criminal justice. Second, the effect of perceived minority police presence is not significantly different for white versus black or Hispanic respondents and for respondents in white neighborhoods versus black neighborhoods, or Hispanic neighborhoods, or minority neighborhoods, indicating that the effect of perceived minority police presence is not more pronounced for black and Hispanic respondents and for respondents in minority neighborhoods. Third, the effect of perceived minority police presence is similar to Hispanic respondents in Hispanic neighborhoods versus Hispanic respondents in white and integrated neighborhoods, suggesting that the level of exposure to other and

18 The effect of perceived minority police presence on perceptions of criminal injustice is significantly different between black and Hispanic neighborhoods $(z=2.14, p<.05)$. 


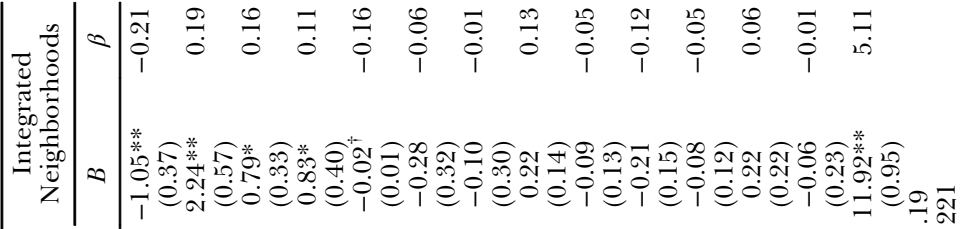

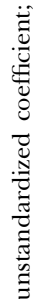

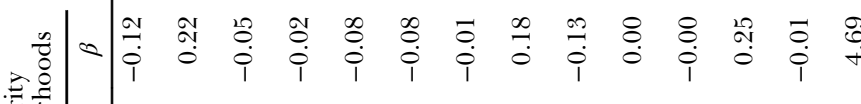

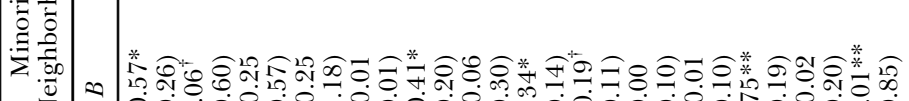
ie-ieiei $i$ ieiei

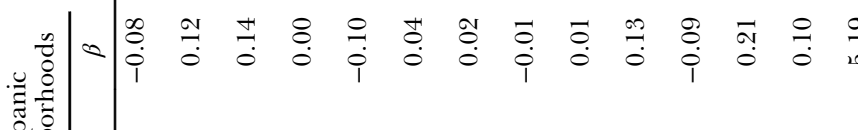

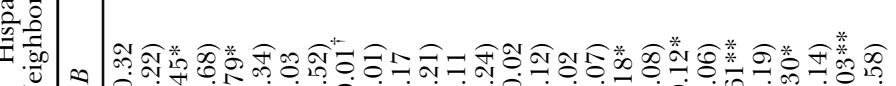

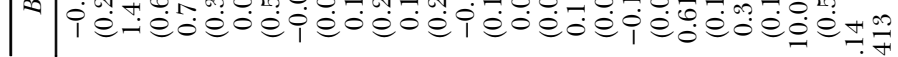

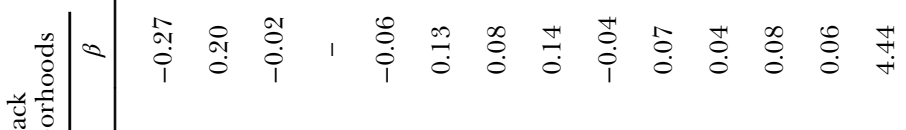

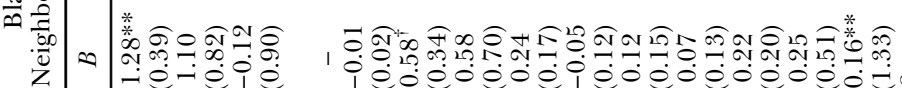

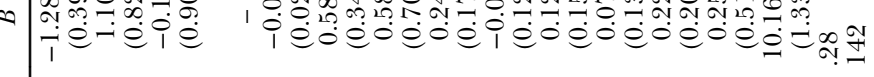

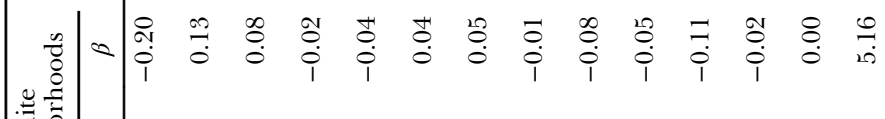

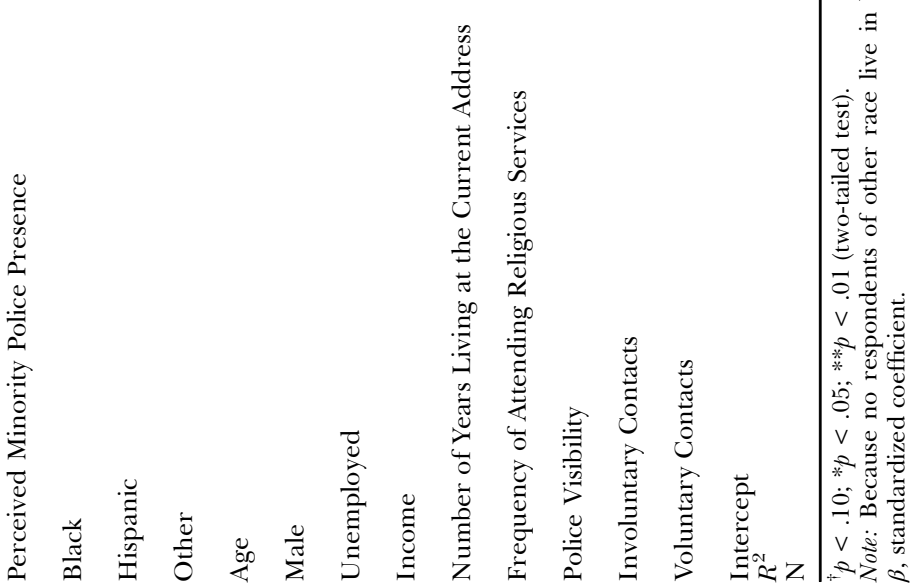


Table 4. Regression of Perceptions of Criminal Injustice for Black and Hispanic Respondents in Black and Hispanic Neighborhoods Versus Integrated and White Neighborhoods

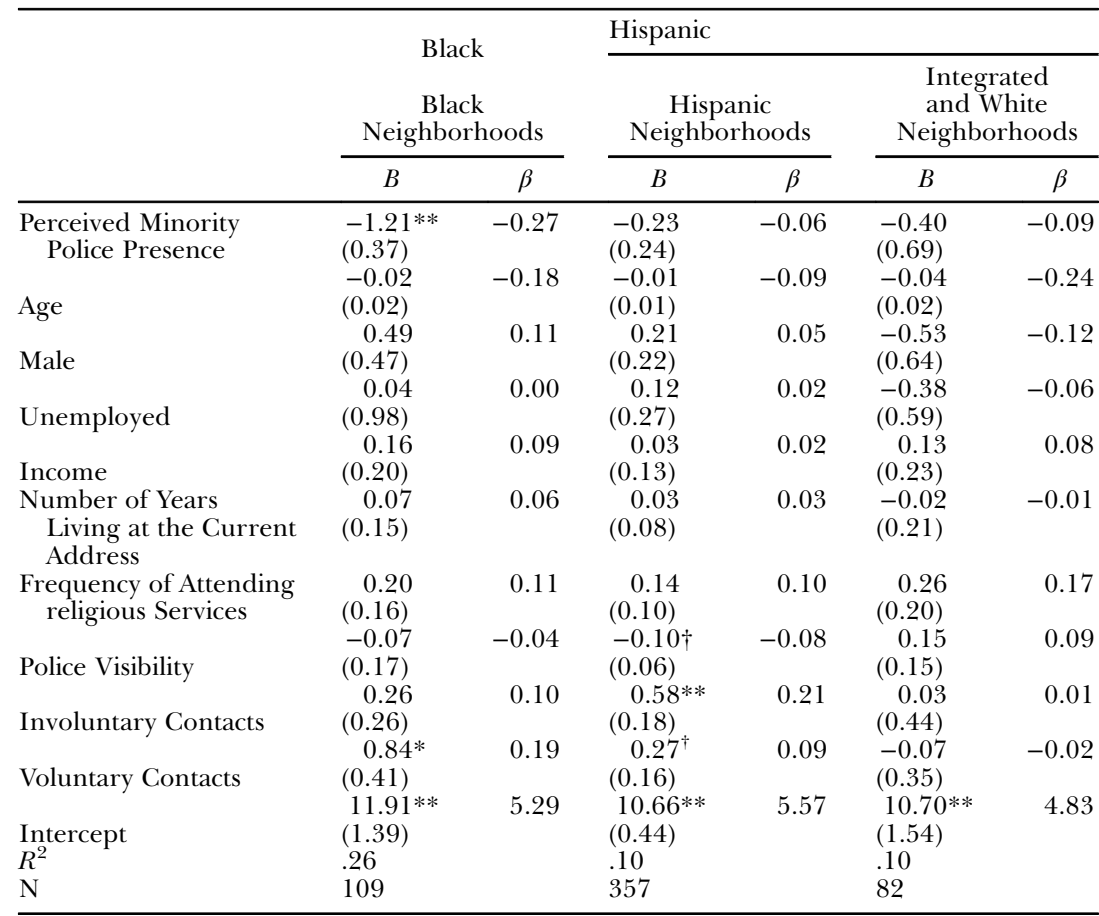

${ }^{7} p<.10 ; * p<.05 ; * * p<.01$ (two-tailed test).

Note: Because very few black respondents live in integrated and white neighborhoods $(\mathrm{N}=13)$, we could not assess the effect of perceived minority police presence on black perceptions of criminal injustice in integrated and white neighborhoods. Thus, we only present OLS for black respondents in black neighborhoods. $B$, unstandardized coefficient; $\beta$, standardized coefficient.

more advantaged groups in a surrounding neighborhood does not seem to moderate the effect of perceived minority police presence on Hispanic respondents' perceptions of criminal injustice.

Two additional findings bear discussion. First, all the findings related to Hispanic respondents or Hispanic neighborhoods in Tables 2-4 suggest that perceived minority police presence has a weak to no effect on perceptions of criminal injustice for Hispanic communities. Instead, involuntary police contacts consistently have the largest effect on perceptions of criminal injustice for Hispanic communities as involuntary contacts have the largest standardized coefficient in models of Hispanic respondents, Hispanic neighborhoods, and Hispanic respondents in Hispanic neighborhoods (see Tables 2-4). Why? We speculate that Hispanic residents, who are less familiar with police harassment than black residents, may fear that their contacts with the police place them in a similar risk status as black residents (Hagan et al. 2005). Thus, for Hispanic residents, police stops are more likely to provoke perceptions of injustice than 
any other factors. This finding is consistent with prior research suggesting that Hispanic residents' attitudes toward police are positive until they have experience with them (e.g., Carter 1985; Skogan et al. 2002).

However, perceived minority police presence has a statistically significant effect in black neighborhoods, and its effect in black neighborhoods is significantly greater than that in Hispanic neighborhoods (see note 18). Similarly, perceived minority police presence has a significantly stronger effect for black respondents than Hispanic respondents (see note 14). In addition, perceived minority police presence consistently has the largest influence on residents' perceptions of criminal injustice for black communities as it has the largest standardized coefficient in models of black respondents, black neighborhoods, and black respondents in black neighborhoods (see Tables 2-4). These findings combined suggest that due to long-standing tensions between police and black communities, black residents may be in a heightened state of sensitivity to minority police presence, and other factors may not matter as much. That said, we find that involuntary police contacts have a statistically significant effect on perceptions of criminal injustice for black respondents but not in black neighborhoods or for black respondents in black neighborhoods. Given that involuntary contacts do not provoke black respondents' perceptions of criminal injustice in black neighborhoods, we speculate that black residents in black neighborhoods, a more homogeneous racial environment, may be familiar with police harassment and in turn conditioned to expect more police stops. The experience of police stops thus results in less outrage and a weak effect on perceptions of criminal injustice for black residents in black neighborhoods. However, black residents in other racial environments may develop multiple reference groups, which allows them to compare more easily their experiences to white residents and other racial groups (Brooks 2000: 1219). Observing differential treatments for other racial groups may lead involuntary contacts to be perceived as more outrageous in other neighborhoods than in black neighborhoods where involuntary police contacts are familiar and expected experiences. Therefore, involuntary contacts may have a strong effect on black perceptions of criminal injustice in other neighborhoods. To assess this possibility, we run a model predicting black perceptions of criminal injustice in other neighborhoods and found that the effect of involuntary contacts is positive and statistically significant $(b=.86$, s.e. $=0.22, p<.01)$. A $z$-test indicates that the effect of involuntary police contacts in other neighborhoods is significantly greater than that in black neighborhoods ( $z=1.76, p<.05$, one-tailed test). Overall, there may be significant differences in Hispanic and black residents' experiences with the police that should be taken into account in making comparisons (Hagan et al. 2005). Future research 
may further examine how and why the effect of minority police presence, perceived and actual, on perceptions of criminal injustice differs for differential racial and ethnic groups and neighborhoods of different racial and ethnic contexts.

Second, we find that income is positively related to residents' perceptions of criminal injustice in the full sample analysis; in analyses separately conducted for white, black, and Hispanic respondents, income is positively and significantly related to perceptions of criminal injustice for black respondents alone. Thus, the significant effect of income for the full sample might be largely driven by the black subsample, and high-income black respondents perceive more criminal injustice than low-income black respondents (see also Brooks and Jeon-Slaughter 2001; Hagan and Albonetti 1982; Peek et al. 1981). Using a comparative perspective (Brooks 2000), we speculate that low-income black residents work and live in racially segregated communities where police scrutiny is more common, and thus they may have lower expectations from the police. However, high-income black residents can move "widely in the mainstream of the American life", and in turn "may be caught off guard when their status does not protect them from police harassment" (Hagan et al. 2005: 385; see also Vega 2016). Future research may investigate how and why income has differential effects on perceptions of criminal injustice for different racial and ethnic groups.

Several implications emerge from this study's findings. First, our findings suggest that improving perceived minority police presence may produce more trust and legitimacy among residents, which may be a key step in "creating greater harmony between the police and the citizenry in the United States" (Riccucci et al. 2018: 516). In particular, given the long history of tensions between minorities and the police, enhancing perceived minority police presence may improve the relations of law enforcement agencies and minority communities, especially black communities. In addition, given how consequential individual perceptions of criminal injustice are for violence and crime control efforts (Kirk and Matsuda 2011), increasing perceived minority police presence may also reduce crime and improve neighborhood conditions in minority communities.

Second, our findings reaffirm Tyler and Wakslak's (2004) assessment suggesting the value of psychology as a framework within which to approach issues of policing. In this article, we focus on perceived neighborhood minority police presence, not the objective measure. Whereas it may be highly likely that perceiving more minority police presence is related to the actual minority police presence, this is not necessarily the case, and the objective and perceptual measures are not fully interchangeable, because individuals' estimates of the minority presence may be inaccurate and the degree of imprecision may 
not be constant across individuals (Pickett et al. 2012). However, to expect minority police presence to have a direct effect on individual perceptions of criminal injustice, minority police presence needs to be first perceived, or misperceived, by residents. It is therefore critical to investigate the factors that affect individual perceptions of minority police presence.

In particular, residents may base their perceptions on their direct observations of encounters or officers passing by in a marked vehicle. They might have systematic bias in the way they perceive the race/ ethnicity of officers who patrol their neighborhoods, and it is possible that residents form their perceptions based on secondary sources (Rosenbaum et al. 2005). Moreover, a range of factors, such as time spent away from one's neighborhood, the race of a person's most proximate interaction with the police, how often one sees the police, the type of neighborhood that a person lives in, and an individual's racial attitudes, may play a role in shaping their perceptions of minority police presence. Furthermore, future research may examine how actual minority police presence affects individual perceptions of criminal injustice and if it affects perceptions of criminal injustice through objective police behavior. If an objective measure at neighborhood level is not available, future research may want to collect data from different cities, conduct multilevel analysis, and assess if and how actual minority representation in local police departments and residents' perceptions of minority police presence, independently and interactively, affect their perceptions of criminal injustice.

Third, our findings suggest that the group-position thesis and the representative bureaucracy theory may be extended to explain the effect of perceived minority police presence on individual perceptions of criminal injustice. ${ }^{19}$ This finding, however, must be interpreted with caution because, when based on cross-sectional data, causal ordering must be assumed. Based on the logic and reasoning intimated by the group-position thesis and the representative bureaucracy theory, we assume that perceived minority police presence affects individual perceptions of criminal injustice, but the opposite causal ordering is not implausible. For example, respondents who perceive a higher level of criminal injustice may be more likely to perceive nonwhites as composing a small share of the police force. This

${ }^{19}$ To integrate conventional measures that capture the definition of the groupposition thesis through a multilevel approach, we aggregated block groups to census tracts and found that census-tract-level racial and ethnic composition, a measure commonly used as a proxy when testing this thesis, did not significantly affect perceptions of criminal injustice (results available upon request). We argue that when applied to individual perceptions of criminal injustice, the definition of the group-position thesis might be better captured by minority representation of criminal justice agents than aggregate measures of minority composition. Future research may assess if aggregate measures of minority composition affect minority representation of criminal justice agents (both actual and perceived), which in turn affect perceptions of criminal injustice. 
possibility may operate simultaneously with the causal ordering assumed in this study. To test this possibility, we estimate a nonrecursive model, treating frequency of attending religious services, employment, block-group-level percent black, and percent Hispanic as instrumental variables. ${ }^{20}$ This nonrecursive model indicates that perceptions of criminal injustice do not significantly predict perceptions of minority police presence. Future research should further and fully explore the possibility that perceptions of minority police presence and criminal injustice simultaneously affect each other. Ultimately, experiments may be needed to test the causal sequence outlined in this study.

In addition, future research may extend beyond this study by investigating a series of related questions. For example, how does the heterogeneity of the nonwhite category in our key independent variable-perceived minority police presence-affect perceptions of criminal injustice? We find that perceiving officers in their neighborhood as not mostly white, thus diversity of any type, improves perceptions of justice. However, it is unknown the extent to which diversity in this category across neighborhoods influences the results. Furthermore, it is unknown if perceiving mostly black officers will impact Hispanic residents' perceptions of criminal injustice or if perceiving mostly Hispanic officers will influence black residents' perceptions of criminal injustice. Although extremely important, these questions may be beyond the scope of this paper. To assess these questions, we will need to collect new data. Moreover, we will need to draw upon other perspectives and likely other disciplines, such as social psychology, because the group-position thesis seems illequipped to do so. For example, in extending Blumer's groupposition model to interethnic attitudes, Bobo and Hutchings (1996: 956) maintain that members of a racial group who feel alienated and oppressed are more likely to view other racial groups as competitive threats to their own group's social position, and "feelings of racial alienation emerge from historical experiences and the current social, political, and economic niches that are typically occupied by members of a racial group." They further find that black respondents, closely followed by Hispanic respondents, are most likely to see other groups as competitive threats, and non-Latino white respondents are the least likely. Therefore, a higher proportion of officers of their own race, actual or perceived, may promote higher levels of perceived justice among minorities, and this effect may be stronger

${ }^{20}$ Whereas causation flows in only one direction in recursive models, nonrecursive models "allow for the estimation of relationships between variables in which each is hypothesized to have a direct impact on the other" (Finch and French 2015: 416). Nonrecursive models, which require the use of instrumental variables to achieve identification, have been used to model outcomes in diverse fields, such as sociology and health (Finch and French 2015: 416). 
for black respondents than Hispanic respondents. Future research may empirically examine these questions using appropriate data, and researchers may conduct in-depth interviews on residents' attitudes toward officers of different racial and ethnic background and their attitudes toward teams of mixed-race officers. These inquires can provide insights into the possible mechanisms linking minority police presence and residents' perceptions of criminal injustice.

Fourth, researchers may need to draw upon a range of theoretical perspectives and mechanisms in explaining the effect of minority police presence on individual perceptions of criminal injustice. We derive this implication for two reasons. The first reason is that we find limited support for the group-position thesis and the representative bureaucracy theory. Although we find that perceived minority police presence affects residents' perceptions of criminal injustice, supporting the group-position thesis and the representative bureaucracy theory, we do not find significantly greater effects of perceived minority police presence for minority respondents or minority neighborhoods, which is contrary to what the group-position thesis and the representative bureaucracy theory would have expected. Future research may further assess to what extent the group-position thesis and the representative bureaucracy theory are supported. The second reason is that the amount of explained variance for perceptions of criminal injustice is relatively small $\left(R^{2}\right.$ ranging from .08 for Hispanic respondents to .20 for black respondents and from .10 for white neighborhoods to .28 for black neighborhoods) but consistent with earlier findings (see, for example, Hagan et al. 2005: table 2). Although our current model does a better job in explaining perceptions of criminal injustice for black residents and residents in black neighborhoods in Los Angeles, a large amount of variance in residents' perceptions of criminal injustice remains unexplained. Future research may further explore what additional factors predict perceptions of criminal injustice. For example, police misconduct, whether experienced directly or heard about secondhand, may impact perceived injustice. Also, the effect of involuntary contacts on perceptions of injustice may be conditioned by the degree of misconduct and/or intrusiveness (Tyler et al. 2014). In addition, our study lacks the important correlates to perceptions of criminal injustice, such as measures of procedural justice and legitimacy. Although we could not include these important correlates because they were not present in the data, future research may include them when explaining perceptions of injustice.

Fifth, scholars may also want to examine the effect of minority police presence, perceived and actual, using data collected in more recent years and from other cities. In this study, we addressed a highly relevant and contemporary problem with old data that are unique in providing a perceptual measure of minority police presence. 
Furthermore, our data were collected after the LAPD had experienced a decade of policing crises, beginning with the beating of Rodney King in 1991 and culminating in the Rampart police corruption scandal in 1999, which resulted in the LAPD entering a consent decree in 2000 to adopt various reform measures (Stone et al. 2009: i). Similarly, since the fatal shooting of 18-year-old Michael Brown in Ferguson, Missouri, in August 2014, there have been renewed calls for local police departments to recruit more minority officers. Police departments in a number of cities where high-profile police killings of black residents happened entered consent decrees with the Justice Department and agreed on various reform efforts. Thus, if we did not find a significant relationship between perceived minority police presence and individual perceptions of criminal injustice in our data, it may suggest no significant relationship today in other places. Regardless, the use of old data precludes us from informing recent police sentiments, which remains a limitation. Recent police shootings may have significantly impacted the hypothesized effect of minority police presence on residents' perceptions of criminal injustice, especially for minority residents and minority communities. Beyond this speculation, we suggest that future research collect new data across a wide range of cities to address recent police sentiments. Moreover, our household survey data do not include those who may have the most critical views about police, such as the homeless and incarcerated. Since perceptions of criminal justice may be even more consequential for their interactions with police, future research may want to find ways to include the homeless and incarcerated in surveys that assess perceptions of criminal justice and especially focus on what factors could improve their perceptions.

One policy intervention derived from this study is to assess whether actually putting more minority officers on the street will alter individual perceptions of minority police presence. Future research may compare what residents perceive about minority police presence to the reality, using perhaps dispatch records that also document back-ups or systematic social observation, which can be compared with what residents report in follow-up surveys about those incidents. Such an analysis might help law enforcement agencies to design strategies that they can adopt to affect residents' perceptions of minority police presence. For example, if a mixed-race team of officers tends to generate a higher level of perceived minority police presence, then police chiefs may want to spread out their minority police presence by ensuring that all police patrol patterns or teams are mixed race. Ultimately, recruiting more minority officers and optimizing patrol assignments of minority officers to various neighborhoods, especially in places where recent police shootings have significantly damaged the relationship between police and local communities, may be able to affect individual 
perceptions of minority police presence, which in turn may improve individual perceptions of criminal justice. That said, reforms should not simply focus on improving perceptions of justice, which, in the absence of improving objective measures of police practices, is not sufficient. Given the problems in those places, such as police department engaging in a pattern of unconstitutional use of force, reforms should also focus on improving objective policing, such as adopting use of force practices that minimize the use of force, implementing policies and developing training to improve interactions with vulnerable people, implementing a robust system of true community policing, and ensuring that officers police fairly and compassionately in all neighborhoods (see U.S. Department of Justice, Civil Rights Division 2015; U.S. Department of Justice, Civil Rights Division, and U.S. Attorney's Office Northern District of Illinois 2017). These should be important policy goals because if a police force is unjust, improving perceptions of minority police presence in order to promote perceptions of justice would be counterproductive to the goal of organizing community members to effectively challenge the objective problems in that police force.

In conclusion, our findings suggest that perceived minority police presence may help to build trust and confidence in police for residents of different race/ethnicity and residents in different types of ethnoracial neighborhoods. Although this study overcomes important limitations from previous research by examining perceived neighborhood minority police presence and its effect for residents of different race/ ethnicity, especially Hispanic residents, and by investigating "cognitive landscapes" (Sampson and Bartusch 1998), our findings may be limited due to the use of the relatively old, observational data collected in Los Angeles. Future research may use experimental designs and collect new data across a wide range of cities to examine the role of minority police presence, perceived and actual, for individual perceptions of criminal injustice and other outcomes, such as procedural justice and police legitimacy. Ultimately, as reliable evidence accumulates, the benefits of racial diversification on improving objective policing practices and bridging the racial gap in police trust will be more than just assumed (Legewie and Fagan 2016).

\section{References}

Acock, Alan (2005) "Working with Missing Values," $67 \mathrm{~J}$. of Marriage and Family 1012-28.

Adelman, Robert (2004) "Neighborhood Opportunities, Race, and Class: The Black Middle Class and Residential Segregation," 3 City E Community 43-63.

Alba, Richard, John Logan, \& Paul Bellair (1994) "Living with Crime: The Implications of Racial/Ethnic Differences in Suburban Location," 73 Social Forces 395-434. 
Allison, Paul (2000) "Multiple Imputation for Missing Data: A Cautionary Tale," 28 Sociological Methods and Research 301-9.

Alpert, Geoffrey \& Roger Dunham (1998) An Analysis of Police Use-of-Force Data. Washington, DC: National Institute of Justice.

- (2004) Understanding Police Use of Force: Officers, Suspects, and Reciprocity. Cambridge: Cambridge Univ. Press.

Antonovics, Kate \& Brian Knight (2009) "A New Look at Racial Profiling: Evidence from the Boston Police Department," 91 Rev. of Economics and Statistics 163-77.

Anwar, Shamena \& Hanming Fang (2006) "An alternative test of racial prejudice in motor vehicle searches: Theory and evidence," 96 American Economic Review $127-51$.

Barlow, David \& Melissa Barlow (2000) Police in a Multicultural Society: An American Story. Prospect Heights, IL: Waveland Press.

Bayley, David \& Harold Mendelsohn (1969) Minorities and the Police: Confrontation in America. New York, NY: Free Press.

Bell, Monica C. (2016) "Situational Trust: How Disadvantaged Mothers Reconceive Legal Cynicism,” 50 Law E Society Rev. 314-47.

Blumer, Herbert (1958) "Race Prejudice as a Sense of Group Position," 1 The Pacific Sociological Rev. 3-7.

Bobo, Lawrence \& Vincent Hutchings (1996) "Perceptions of Racial Group Competition: Extending Blumer's Theory of Group Position to a Multiracial Social Context," 61 American Sociological Rev. 951-72.

Brooks, Richard (2000) "Fear and Fairness in the City: Criminal Enforcement and Perceptions of Fairness in Minority Communities," 73 Southern California Law Rev. 1219-73.

Brooks, Richard \& Hackyung Jeon-Slaughter (2001) "Race, Income and Perceptions of the U.S. Court System," 19 Behavioral Sciences \& the Law 249-64.

Brown, Ben \& Wm Reed Benedict (2002) "Perceptions of the Police: Past Findings, Methodological Issues, Conceptual Issues and Policy Implications," 25 Policing 543-80.

Brown, Robert \& James Frank (2006) "Race and Officer Decision Making: Examining Differences in Arrest Outcomes between Black and White Officers," 23 Justice Q. 96-126.

Brunson, Rod (2007) “"Police don't Like Black People”: African American Young men's Accumulated Police Experiences," 6 Criminology and Public Policy $71-101$.

Brunson, Rod \& Jacinta Gau (2015) "Officer Race Versus Macro-Level Context: A Test of Competing Hypotheses about Black citizens' Experiences with and Perceptions of Black Police Officers," 61 Crime E Delinquency 213-42.

Brunson, Rod \& Jody Miller (2006) "Young Black Men and Urban Policing in the United States," 46 British J. of Criminology 613-40.

Cao, Liqun, Xiaogang Deng, \& Shannon Barton (2000) "A Test of Lundman's Organizational Product Thesis with Data on Citizen Complaints," 23 Policing 356-73.

Cao, Liqun \& Bu Huang (2000) "Determinants of Citizen Complaints against Police Abuse of Power," $28 \mathrm{~J}$. of Criminal Justice 203-13.

Carter, David (1985) "Hispanic Perceptions of Police Performance: An Empirical Assessment," 13 J. of Criminal Justice 487-500.

Chiricos, Ted, Michael Hogan, \& Marc Gertz (1997) "Racial Composition of Neighborhood and Fear of Crime," 35 Criminology 107-32.

Chiricos, Ted, Ranee McEntire, \& Marc Gertz (2001) "Perceived Racial and Ethnic Composition of Neighborhood and Perceived Risk of Crime," 48 Social Problems 322-40.

Close, Billy R. \& Patrick L. Mason (2006) "After the traffic stops: Officer characteristics and enforcement actions," 6 Topics in Economic Analysis \& Policy 1-41. 
Close, Billy R. \& Patrick Leon Mason (2007) "Searching for efficient enforcement: Officer characteristics and racially biased policing," 3 Review of Law E Economics 263-321.

Curtin, Richard, Stanley Presser, \& Eleanor Singer (2000) "The Effects of Response Rate Changes on the Index of Consumer Sentiment," 64 Public Opinion Q. 413-28.

(2005) "Changes in Telephone Survey Nonresponse over the Past Quarter Century,” 69 Public Opinion Q. 87-98.

Decker, Scott (1981) "Citizen Attitudes toward the Police: A Review of Past Findings and Suggestions for Future Policy," $9 \mathrm{~J}$. Police Science and Administration 80-7.

Decker, Scott \& Russell Smith (1980) "Police Minority Recruitment," 8 J. Criminal Justice 387-93.

Elliott, Irina, Stuart Thomas, \& James Ogloff (2011) "Procedural Justice in Contacts with the Police: Testing a Relational Model of Authority in a Mixed Methods Study," 17 Psychology, Public Policy, and Law 592-610.

Engel, Robin (2005) "Citizens' Perceptions of Distributive and Procedural Injustice during Traffic Stops with Police," 42 J. Research in Crime and Delinquency 445-81.

Epp, Charles, Steven Maynard-Moody, \& Donald Haider-Markel (2014) Pulled over: How Police Stops Define Race and Citizenship. Univ. of Chicago Press.

Fagan, Jeffrey, Anthony Braga, Rod Brunson, \& April Pattavina (2016) "Stops and Stares: Street Stops, Surveillance, and Race in the New Policing," 43 Fordham Urban Law J. 539-614.

Finch, W. Holmes \& Brian F. French (2015) "Modeling of Nonrecursive Structural Equation Models with Categorical Indicators," 22 Structural Equation Modeling: A Multidisciplinary J. 416-28.

Frank, James, Steven Brandl, Francis Cullen, \& Amy Stichman (1996) "Reassessing the Impact of Race on citizens' Attitudes toward the Police: A Research Note," 13 Justice Q. 321-34.

Forman, James, Jr. (2002) "Children, Cops, and Citizenship: Why Conservatives Should Oppose Racial Profiling," in Mauer, M. \& M. Chesney-Lind, eds., Invisible Punishment. New York, NY: New Press.

- (2017) Locking Up Our Own: Crime and Punishment in Black America. New York, NY: Farrar, Straus and Giroux.

Geller, William \& Kevin Karales (1981) "Shootings of and by Chicago Police: Uncommon Crises Part I: Shootings by Chicago Police," $72 \mathrm{~J}$. of Criminal Law and Criminology 1813-66.

Gilliard-Matthews, Stacia, Brian Kowalski, \& Richard Lundman (2008) "Officer Race and Citizen-Reported Traffic Ticket Decisions by Police in 1999 and 2002," 11 Police Q. 202-19.

Ginwright, Shawn (2002) "Classed Out: The Challenges of Social Class in Black Community Change," 49 Social Problems 544-62.

Hagan, John \& Celesta Albonetti (1982) "Race, Class and the Perception of Criminal Injustice in America," 88 American J. of Sociology 329-55.

Hagan, John, Carla Shedd, \& Monique Payne (2005) "Race, Ethnicity, and Youth Perceptions of Criminal Injustice," 70 American Sociological Rev. 381-407.

Hickman, Matthew \& Alex Piquero (2009) "Organizational, Administrative, and Environmental Correlates of Complaints about Police Use of Force: Does Minority Representation Matter?” 55 Crime E Delinquency 3-27.

Hong, Sounman (2017a) "Does Increasing Ethnic Representativeness Reduce Police Misconduct? Evidence from Police Reform in England and Wales," 77 Public Administration Rev. 195-205.

- (2017b) "Black in Blue: Racial Profiling and Representative Bureaucracy in Policing Revisited," 27 J. of Public Administration Research and Theory 547-61.

Howell, Susan, Huey Perry, \& Matthew Vile (2004) "Black Cities, White Cities: Evaluating the Police," 26 Political Behavior 45-68. 
Huebner, Beth, Joseph Schafer, \& Timothy Bynum (2004) "African American and White Perceptions of Police Services," $32 \mathrm{~J}$. of Criminal Justice 123-35.

Johnson, Valerie (2012) Black Power in the Suburbs: The Myth or Reality of African American Suburban Political Incorporation. SUNY Press.

Keeter, Scott, Courtney Kennedy, Michael Dimock, Jonathan Best, \& Peyton Craighill (2006) "Gauging the Impact of Growing Nonresponse on Estimates from a National RDD Telephone Survey," 70 Public Opinion Q. 759-79.

Kirk, David \& Mauri Matsuda (2011) "Legal Cynicism, Collective Efficacy, and the Ecology of Arrest," 49 Criminology 443-72.

Kirk, David \& Andrew Papachristos (2011) "Cultural Mechanisms and the Persistence of Neighborhood Violence," 116 American J. of Sociology 1190-233.

Klinger, David (1997) "Negotiating Order in Patrol Work: An Ecological Theory of Police Response to Deviance," 35 Criminology 277-306.

Kochel, Tammy (2017) "Explaining Racial Differences in Ferguson's Impact on Local residents' Trust and Perceived Legitimacy: Policy Implications for Police," Criminal Justice Policy Rev.

Langan, Patrick, Lawrence Greenfeld, Steven Smith, Matthew Durose, \& David Levin (2001) Contacts between Police and the Public: Findings from the 1999 National Survey. Washington, DC: U.S. Department of Justice.

Lasley, James (1994) "Ethnicity, Gender, and Police-Community Attitudes," 75 Social Science Q. 85-97.

Legewie, Joscha and Jeffrey Fagan. 2016. Group threat, police officer diversity, and the deadly use of police force. Columbia Public Law Research Paper No. 14-512.

Logan, John \& Brian Stults (1999) "Racial Differences in Exposure to Crime: The City and Suburbs of Cleveland in 1990," 37 Criminology 251-76.

Mansbridge, Jane (1999) "Should Blacks Represent Blacks and Women Represent Women? A Contingent "Yes"," $61 \mathrm{~J}$. of Politics 628-57.

Martinez, Ramiro, Jr. (2007) "Incorporating Latinos and Immigrants into Policing Research," 6 Criminology and Public Policy 57-64.

McCarty, Christopher, Mark House, Jeffrey Harman, \& Scott Richards (2006) "Effort in Phone Survey Response Rates: The Effects of Vendor and Client-Controlled Factors," 18 Field Methods 172-88.

McElvain, James \& Augustine Kposowa (2004) "Police Officer Characteristics and Internal Affairs Investigations for Use of Force Allegations," 32 J. of Criminal Justice 265-79. - (2008) "Police Officer Characteristics and the Likelihood of Using Deadly Force," 35 Criminal Justice and Behavior 505-21.

Morin, Rich, \& Renee Steple (2016) The Racial Confidence Gap in Police Performance. Available at: http://assets.pewresearch.org/wp-content/uploads/sites/3/2016/09/ST_2016.09.29_Police-Final.pdf (accessed 5 July 2019).

Murphy, Kristina, Lyn Hinds, \& Jenny Fleming (2008) "Encouraging Public Cooperation and Support for Police," 18 Policing \& Society 136-55.

Muthén, Linda \& Bengt Muthén (1998-2012) Mplus User's Guide, 7th ed. Los Angeles, CA: Muthén and Muthén.

National Advisory Commission on Civil Disorders (1968) Report of the National Advisory Commission on Civil Disorders. Washington, DC: GPO.

Nicholson-Crotty, Sean, Jill Nicholson-Crotty, \& Sergio Fernandez (2017) "Will more Black Cops Matter? Officer Race and Police-Involved Homicides of Black Citizens," 77 Public Administration Rev. 206-16.

Novak, Kenneth, Joshua Cochran, \& Patricia Warren (2012) "Racial, Ethnic, and Gender Differences in Perceptions of the Police," $28 \mathrm{~J}$. of Contemporary Criminal Justice 206-27.

Ozkan, Turgut, John Worrall, \& Alex Piquero (2016) "Does Minority Representation in Police Agencies Reduce Assaults on the Police?" 41 American J. of Criminal Justice 402-23. 
Paternoster, Raymond, Robert Brame, Paul Mazerolle, \& Alex Piquero (1998) "Using the Correct Statistical Test for the Equality of Regression Coefficients," 36 Criminology 859-66.

_ (2005) "Black Middle-Class Neighborhoods," 31 Annual Rev. of Sociology 305-29.

(2013) Black Picket Fences: Privilege and Peril among the Black Middle Class. Univ. of Chicago Press.

Peek, Charles, George Lowe, \& Jon Alston (1981) "Race and Attitudes toward Local Police: Another Look," $11 \mathrm{~J}$. of Black Studies 361-74.

Peterson, Ruth \& Lauren Krivo (2010) Divergent Social Worlds: Neighborhood Crime and the Racial-Spatial Divide. New York, NY: Russell Sage Foundation.

Pickett, Justin, Ted Chiricos, Kristin Golden, \& Marc Gertz (2012) "Reconsidering the Relationship between Perceived Neighborhood Racial Composition and whites' Perceptions of Victimization Risk: Do Racial Stereotypes Matter?” 50 Criminology $145-86$.

President's Task Force on 21 st Century Policing (2015) Final Report of the President's Task Force on 21st Century Policing. Washington, DC: Office of Community Oriented Policing Services.

Quillian, Lincoln (1995) "Prejudice as a Response to Perceived Group Threat: Population Composition and Anti-Immigrant and Racial Prejudice in Europe," 60 American Sociological Rev. 586-611.

Reaves, Brian \& Matthew Hickman (2002) Police Departments in Large Cities, 1990-2000. Bureau of Justice Statistics Special Report. Washington, DC: U.S. Department of Justice.

Reisig, Michael, Jason Bratton, \& Marc Gertz (2007) "The Construct Validity and Refinement of Process-Based Policing Measures," 34 Criminal Justice and Behavior 1005-28.

Reisig, Michael \& Roger Parks (2000) "Experience, Quality of Life, and Neighborhood Context," 17 Justice Q. 607-29.

Riccucci, Norma M., Gregg G. Van Ryzin, \& Karima Jackson (2018) "Representative Bureaucracy, Race, and Policing: A Survey Experiment," $28 \mathrm{~J}$. of Public Administration Research and Theory 506-18.

Rojek, Jeff, Richard Rosenfeld, \& Scott Decker (2012) "Policing race: The racial stratification of searches in police traffic tops," 50 Criminology 993-1024.

Rosenbaum, Dennis, Amie Schuck, Sandra Costello, Darnell Hawkins, \& Marianne Ring (2005) "Attitudes toward the Police: The Effects of Direct and Vicarious Experience," 8 Police Q. 343-65.

Sampson, Robert \& Dawn Jeglum Bartusch (1998) "Legal Cynicism and (Subcultural?) Tolerance of Deviance: The Neighborhood Context of Racial Differences," 32 Law and Society Rev. 777-804.

Scaglion, Richard \& Richard Condon (1980) "Determinants of Attitudes toward City Police," 17 Criminology 485-94.

Schafer, Joseph (1999) "Multiple imputation: A primer," 8 Statistical Methods in Medical Research 3-15.

Semyonov, Moshe, Rebeca Raijman, Anat Yom Tov, \& Peter Schmidt (2004) "Population Size, Perceived Threat, and Exclusion: A Multiple Indicators Analysis of Attitudes toward Foreigners in Germany," 33 Social Science Research 681701.

Sharp, Elaine (2014) "Minority Representation and Order Maintenance Policing: Toward a Contingent View," 95 Social Science Q. 1155-71.

Sherman, Lawrence (1983) "After the Riots: Police and Minorities in the United States," in Glazer, N. \& K. Young, eds., Ethnic Pluralism and Public Policy. Toronto, ON: Lexington.

Skogan, Wesley (1979) "Citizen Satisfaction with Police Services," in Baker, Ralph \& Fred Meyer, eds., Evaluating Alternative Law Enforcement Policies. Lexington, MA: Lexington Books. 
Skogan, Wesley, Lynn Steiner, Jill Du Bois, J. Erik Gudell, \& Aimee Fagan (2002) Community Policing and the "New Immigrants": Latinos in Chicago. Washington, DC: National Institute of Justice.

Skogan, Wesley G. \& Kathleen Frydl (2004) Fairness and Effectiveness in Policing: The Evidence. Committee to Review Police Policy and Practices. Washington, DC: National Academies Press.

Smith, Brad (2003) "The Impact of Police Officer Diversity on Police-Caused Homicides," 31 Policy Studies J. 147-62.

Stone, Christopher, Todd Foglesong, \& Christine Cole (2009) Policing Los Angeles under a Consent Decree: The Dynamics of Change at the LAPD. Cambridge: Harvard Kennedy School.

Sun, Ivan \& Brian Payne (2004) "Racial Differences in Resolving Conflicts: A Comparison between Black and White Police Officers," 50 Crime \& Delinquency 516-41.

Sunshine, Jason \& Tom Tyler (2003) "The Role of Procedural Justice and Legitimacy in Shaping Public Support for Policing," 37 Law \& Society Rev. 513-48.

Tankebe, Justice, Michael D. Reisig, \& Xia Wang (2016) "A Multidimensional Model of Police Legitimacy: A Cross-Cultural Assessment," 40 Law and Human Behavior $11-22$.

Theobald, Nick \& Donald Haider-Markel (2009) "Race, Bureaucracy, and Symbolic Representation: Interactions between Citizens and Police," $19 \mathrm{~J}$. of Public Administration Research and Theory 409-26.

Tyler, Tom (2004) "Enhancing Police Legitimacy," 593 The Annals of the American Academy of Political and Social Science 84-99.

- (2005) "Policing in Black and White: Ethnic Group Differences in Trust and Confidence in the Police," 8 Police Q. 322-42.

- (2011) "Trust and Legitimacy: Policing in the USA and Europe," 8 European J. of Criminology 254-66.

Tyler, Tom, Jeffrey Fagan, \& Amanda Geller (2014) "Street Stops and Police Legitimacy: Teachable Moments in Young Urban men's Legal Socialization," $11 \mathrm{~J}$. of Empirical Legal Studies 751-85.

Tyler, Tom R. \& Yuen Huo (2002) Trust in the Law. New York, NY: Russell Sage Foundation.

Tyler, Tom \& Cheryl Wakslak (2004) "Profiling and Police Legitimacy: Procedural Justice, Attributions of Motive, and Acceptance of Police Authority," 42 Criminology 253-81.

Unnever, James, Shaun Gabbidon, \& George Higgins (2011) "The Election of Barack Obama and Perceptions of Criminal Injustice," 28 Justice Q. 23-45.

Unnever, James \& Francis Cullen (2005) "Executing the Innocent and Support for Capital Punishment: Implications for Public Policy," 4 Criminology and Public Policy 3-38.

L (2007a) "Reassessing the Racial Divide in Support for Capital Punishment: The Continuing Significance of Race," $44 \mathrm{~J}$. of Research in Crime and Delinquency $124-58$.

- (2007b) "The Racial Divide in Support for the Death Penalty: Does White Racism Matter?" 85 Social Forces 1-21.

U.S. Department of Justice, Civil Rights Division (2015) Investigation of the Ferguson Police Department; March 4, 2015 Report. Washington, DC: U.S. Government Printing Office.

U.S. Department of Justice, Civil Rights Division, and U.S. Attorney's Office Northern District of Illinois (2017) Investigation of the Chicago Police Department; January 13, 2017 Report. Washington, DC: U.S. Government Printing Office.

Vega, Tanzina. 2016. For Affluent Blacks, Wealth Doesn't Stop Racial Profiling. CNN. https://money.cnn.com/2016/07/14/news/economy/wealthy-blacks-racial-profiling/ index.html (accessed 7 May 2019). 
Wagner, Allen \& Scott Decker (1993) "Evaluating Citizen Complaints against the Police," 2 Critical Issues in Policing: Contemporary Readings 275-91.

Wang, Xia (2012) "Undocumented Immigrants as Perceived Criminal Threat: A Test of the Minority Threat Perspective," 53 Criminology 743-76.

Ward, Geoff (2006) "Race and the Justice Workforce: A System Perspective," in Peterson, R., L. Krivo, \& J. Hagan, eds., The Many Colors of Crime: Inequalities of Race, Ethnicity, and Crime in America. New York, NY: New York Univ. Press.

Weitzer, Ronald (2000) "White, Black, or Blue Cops?” $28 \mathrm{~J}$. of Criminal Justice 313-24. - (2015. Diversity Among Police Officers Is Key, But It Won't Solve the Problems with Policing. The Guardian. https://www.theguardian.com/commentisfree/2015/jan/20/ diversity-among-police-officers-is-key-but-it-wont-solve-the-problems-with-polic ing (accessed 7 May 2019).

Weitzer, Ronald \& Steven Tuch (1999) "Race, Class and Perceptions of Discrimination by the Police," 45 Crime and Delinquency 494-507.

- (2004a) "Reforming the Police: Racial Differences in Public Support for Change," 42 Criminology 391-416.

- (2004b) "Race and Perceptions of Police Misconduct," 51 Social Problems $305-25$.

- (2006) Police and Policing in America: Conflict and Reform. New York, NY: Cambridge Univ. Press.

Weitzer, Ronald, Steven Tuch, \& Wesley Skogan (2008) "Police-Community Relations in a Majority-Black City," $45 \mathrm{~J}$. of Research in Crime and Delinquency 398-428.

Welch, Susan, Sigelman Lee, Timothy Bledsoe, \& Michael Coombs (2001) Race and Place: Race Relations in an American City. New York, NY: Cambridge Univ. Press.

Willits, Dale \& Jeffrey Nowacki (2014) "Police Organisation and Deadly Force: An Examination of Variation across Large and Small Cities," 24 Policing and Society 63-80.

Wortley, Scot, John Hagan, \& Ross Macmillan (1997) "Just Des(s)Erts? The Racial Polarization of Perceptions of Criminal Injustice," 31 Law and Society Rev. 637-76.

Wortley, Scot (1996) "Justice for all? Race and Perceptions of Bias in the Ontario Criminal Justice System-A Toronto Survey," 38 Canadian J. of Criminology 439-67.

Xia Wang is an Associate Professor in the School of Criminology and Criminal Justice at Arizona State University. She is involved in studies of race and ethnicity and their effects on crime and criminal justice, and the use of various analytic techniques to test and extend criminological theories. Her work has appeared in Criminology, Journal of Research in Crime and Delinquency, Journal of Quantitative Criminology, Justice Quarterly, and Law E Society Review. She is the co-recipient of the 2013 American Society of Criminology Division on People of Color and Crime's New Scholar Award and the recipient of the 2013 Outstanding Publication Award from The National White-Collar Crime Center and The White-Collar Crime Research Consortium.

Justin Ready has worked in the School of Criminology and Criminal Justice at Griffith University as a Senior Lecturer since 2016. He received his Ph.D. at Rutgers University, where he served as Project Director in the Centre for Crime Prevention Studies. He later worked as a Senior Research Associate at the Police Foundation in Washington, DC. His 
research focuses on crime hot spots and the impact of new technology on police practices. He is the 2013 recipient of the Young Experimental Scholar Award and the 2016 recipient of the Award for the Outstanding Experimental Field Trial. Recently, he has studied the effects of active shooter incidents on officer memory/cognition, and the impact of body worn video and GPS technology on police management and operations. His publications have appeared in academic journals such as Criminology, the Journal of Experimental Criminology and Justice Quarterly.

Garth Davies is an Associate Professor in the School of Criminology at Simon Fraser University and is the Associate Director of the Institute of Violence, Terrorism, and Security at Simon Fraser University. His current work involves developing a database for evaluating programs for countering violent extremism; the social psychology of radicalization; and the statistical modeling and projection of violent right-wing extremism. He has also been involved in the development of the Terrorism and Extremism Network Extractor (TENE), a web-crawler designed to investigate extremist activities on both the open internet as well as the dark net. He earned his Ph.D. in Criminal Justice from Rutgers University. 